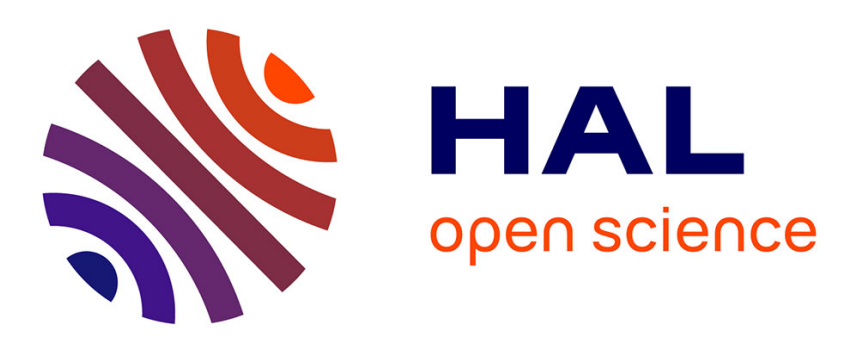

\title{
How language impacts memory of motion events in English and French
}

Helen Engemann, Henriëtte Hendriks, Maya Hickmann, Efstathia Soroli, Coralie Vincent

\section{- To cite this version:}

Helen Engemann, Henriëtte Hendriks, Maya Hickmann, Efstathia Soroli, Coralie Vincent. How language impacts memory of motion events in English and French. Cognitive Processing, 2015, 16 (S1), pp.209-213. 10.1007/s10339-015-0696-7 . hal-03386382

\section{HAL Id: hal-03386382 \\ https://hal.univ-lille.fr/hal-03386382}

Submitted on 18 Nov 2021

HAL is a multi-disciplinary open access archive for the deposit and dissemination of scientific research documents, whether they are published or not. The documents may come from teaching and research institutions in France or abroad, or from public or private research centers.
L'archive ouverte pluridisciplinaire HAL, est destinée au dépôt et à la diffusion de documents scientifiques de niveau recherche, publiés ou non, émanant des établissements d'enseignement et de recherche français ou étrangers, des laboratoires publics ou privés. 


\section{How language impacts memory of motion events in English and French}

Helen Engemann ${ }^{1}$, Henriëtte Hendriks ${ }^{2}$, Maya Hickmann ${ }^{3}$, Efstathia Soroli ${ }^{4}$ \& Coralie Vincent ${ }^{3}$

${ }^{1}$ Free University of Bozen-Bolzano

Competence Centre for Language Studies

Universitätsplatz 1

39100 Bozen/Bolzano, Italy

E-mail: helen.engemann@cantab.net

Tel.: +390471012457

${ }^{2}$ University of Cambridge

Department of Theoretical and Applied Linguistics, Faculty of MML

Sidgwick Avenue

Cambridge CB3 9DA, UK

${ }^{3}$ CNRS - Laboratoire "Structures Formelles du Langage"

\& University of Paris 8

59/61 rue Pouchet

75017 Paris, France

${ }^{4}$ University of Lille 3

\& CNRS - Laboratoire "Savoirs, Textes, Langage"

Rue du Barreau - BP 60149

59653 Villeneuve d'Ascq Cedex, France 


\title{
How language impacts memory of motion events in English and French
}

\begin{abstract}
This paper examines whether cross-linguistic differences in motion encoding affect event processing, specifically memory performance. We compared speakers of two languages which differ strikingly in how they habitually encode MANNER and PATH of motion (Talmy 2000). We tested French and English adult native speakers across three tasks that recruited and/or suppressed verbal processing to different extents: verbal event descriptions elicited on the basis of dynamic motion stimuli, a verbal memory task testing the impact of prior verbalisation on target recognition, and a non-verbal memory task, using a dual-task paradigm to suppress internal verbalisation. Results showed significant group differences in the verbal description task, which mirrored expected typological tendencies. English speakers more frequently expressed both MANNER and PATH information than French speakers, who produced more descriptions encoding either PATH or MANNER alone. However, these differences in linguistic encoding did not significantly affect speakers' memory performance in the memory recognition tasks, neither in the verbal nor in the non-verbal condition. The findings contribute to current debates regarding the conditions under which language effects occur and the relative weight of language-specific and universal constraints on spatial cognition.
\end{abstract}

\section{Keywords}

Spatial cognition, cross-linguistic variation, motion events, memory, language and thought 


\section{Introduction}

Currently revived debates in the Neo-Whorfian tradition concern the cognitive implications of linguistic diversity. In this context, motion events have proven to be a particularly tractable domain of investigation, owing to systematic variation in how and how often basic conceptual components are expressed by speakers of typologically different languages. Talmy (2000) distinguishes two language types according to where the core definitional element of motion, PATH, is expressed (in bold in examples below): Verb-framed languages (e.g. French) lexicalise PATH in the verb, leaving MANNER of motion either implicit or in peripheral devices, such as gerunds or adverbials (example 1); satelliteframed languages (e.g. English) provide compact structures that systematically combine both components by lexicalising MANNER in the verb and PATH outside of the verb, e.g. in particles or prepositions (example 2).

(1) Il traverse la rue en courant He crosses the road by running
PATH
MANNER

(2) He's running across the road. MANNER PATH

Research in the wake of Talmy's influential typology has addressed the question as to whether these language-specific differences go beyond mere verbalisation strategies and to what extent they may also guide aspects of our cognitive processing of motion events (e.g. Slobin 2004). To understand the depth of language impact, recent years have seen an increasing concern to single out language effects on non-verbal aspects of cognition. As a means of tapping into such non-verbal processes, on-line behavioural measures such as reaction times, ERP and eye movements have received increasing attention, across a range of cognitive tasks. Amongst the most extensively researched tasks is categorisation, in both verbal and non-verbal forms (e.g. Choi and Hattrup 2012; Hickmann et al. in press). By comparison, the cognitive faculty of memory and how it may be affected by cross-linguistic differences of motion expression has only been addressed by few studies so far and findings in this domain are mixed. Most of the earlier studies report no impact of language on memory (Gennari et al. 2002; Papafragou et al. 2002). Some later studies attest effects when language is present in some form, either through prior linguistic encoding or simply by giving participants the opportunity to verbalise internally (e.g. Filipović 2011; Papafragou et al. 2008). By contrast, in purely non-verbal conditions, when interference tasks such as tapping or articulatory suppression are used, language effects often disappear (e.g. Trueswell and Papafragou 2010). Reports of language-specific effects on memory in the presence of verbal interference tasks are rare (e.g. Athanasopoulos and Bylund 2013). Moreover, findings suggest that when such effects occur, they are highly sensitive to multiple methodological aspects of the design, such as the presentation mode of stimuli (simultaneous vs. successive) and their visual properties (cartoons vs. naturalistic scenes; static versus dynamic). These altogether 
inconclusive results have generated a growing awareness of the transient nature of language effects, along with a concern for identifying the conditions under which they may occur. In this respect, the presence versus absence of linguistic interference tasks is a crucial factor that warrants further examination. This study aims to contribute to this line of research by comparing three conditions of both verbal and non-verbal behaviour relating to the expression and memory of motion events.

\section{Method}

\section{Participants}

85 monolingual native speakers of French $(\mathrm{N}=44)$ and English $(\mathrm{N}=41)$ participated in the study. They were all university students in England and France. Subjects with a multilingual background or any reported linguistic or cognitive disorder were excluded from the sample. All participants received a monetary reward for their participation. All participants performed a verbal description task, but subjects of each language group were randomly assigned to one of two conditions of a memory task: (i) a non-verbal and (ii) a verbal one.

\section{Stimuli}

Stimuli consisted of black-and-white short video clips that showed naturalistic motion events involving a human agent performing spontaneous displacements that combined one of six PATH types (e.g. ACROSS, INTO, OUT OF, ALONG, UP, DOWN) with one of six MANNER types (e.g. JUMPING, WALKING, RUNNING, CYCLING, ROLLERSKATING, SCOOTERING). The resulting 40 target videos (including four additional filler items) were spread across four groups, so that each subject saw 10 experimental items (plus one initial training item), presented on an external monitor. The order of presentation was fully randomized for each participant.

\section{Tasks and procedure}

The non-verbal memory task was designed to test whether language affects non-verbal event processing. An interference task involving articulatory suppression (syllable repetition) was administered to prevent internal verbalisation. The task involved two phases. In Phase 1, participants were first instructed to view 10 target items while repeating a sequence of syllables ("BaBiBo"). In the immediately following Phase 2, participants saw two variants presented simultaneously on the screen next to one another, one of which was correct, i.e. was equivalent to one of the target videos shown in Phase 1, and one incorrect (mismatch of either MANNER or PATH in relation to the targets). Participants were instructed to decide which of the variants they had seen before (in Phase 1) and to indicate their response by a mouse-click (left or right) as soon as they recognised the matching video. The final task component involved verbal description during which participants were once more 
presented with the target items from Phase 1, and this time they were invited to describe them verbally. The verbal memory condition was identical to the non-verbal counterpart, except that instead of articulatory suppression, Phase 1 prompted subjects to verbally encode the target clips presented to them prior to the recognition phase. The rationale of these tasks was to test the impact of verbalisation on subsequent memory performance (verbal memory condition), in contrast to the maximally nonverbal memory task where no verbal influence was expected, due to articulatory suppression and the fact that descriptions were produced after the memory task.

\section{Hypotheses}

Our hypotheses concerned the occurrence of language effects across the three tasks. Strong effects were predicted for the most verbal task, verbal description: In accordance with typological patterns, English speakers were predicted to conflate PATH and MANNER components more frequently than French speakers, who in turn should encode MANNER to a lesser extent and instead produce more PATH-only responses. As for the memory tasks, the null hypothesis was that speakers' language should not affect their cognitive performance. If language effects emerged, they should mainly occur in the verbal condition, i.e. the verbal memory task, whereas non-verbal memory should either show no language effects or only weak effects. If language was to affect speakers' cognitive processing of motion, we expected French participants to make fewer correct choices in recognition (Phase 2) and specifically, more errors involving MANNER. By contrast, English speakers should not display a skew in error-type ratios.

\section{Results}

\section{Verbal description}

An ANOVA was conducted to determine the effect of the between-subject factor Language (English, French) on the frequencies of responses conflating PATH and MANNER (PM-responses). ${ }^{1}$ In line with predictions, results confirmed that PM-responses were significantly more frequent in English than in French $(\mathrm{F}(1,81)=42.1, \mathrm{p}<0.0001)$. As Fig. 1 illustrates, English event descriptions systematically encoded both information components ( $\mathrm{PM}=90 \%)$.

\section{INSERT FIG. 1}

Although French responses were also often of this type $(\mathrm{PM}=60 \%)$, speakers in this group also produced some descriptions expressing either PATH $(\mathrm{P}=17 \%)$ or MANNER $(\mathrm{M}=18 \%)$ alone. Overall,

\footnotetext{
${ }^{1}$ These results are based on verbal descriptions elicited in Phase 1 of the verbal memory task, to avoid contamination by prior memorisation, as in the non-verbal memory task.
} 
responses encoding MANNER (either as PM or M) were more frequent than expected for French on typological grounds. Examples 3 - 5 show representative responses for both language groups. English descriptions typically used compact structures that conflated both components by combining a main verb encoding MANNER and a particle or preposition expressing PATH (example 3). In French, two main response patterns emerged (see Fig. 1). Firstly, descriptions combining both components (PM) displayed the typologically expected pattern combining a PATH-verb with a gerund or adverbial expressing MANNER (example 4). Secondly, descriptions encoding only one component (P/M) typically expressed PATH or MANNER in a verb (examples in 5).

(3) There's a man jumping down a hill MANNER PATH

(4) C'est une fille qui traverse une rue à trottinette It's a girl who crosses a road by scooter PATH MANNER

(5) a. Un homme sort d'une pièce

A man goes-out of-a room PATH

b. Une femme court sur un chemin

A woman runs on a path

MANNER

\section{Memory tasks}

ANOVAs were conducted to test the effect of language and condition on the following dependent variables: (a) Mean frequencies of correct responses, reflecting how often speakers chose the matching variant in the recognition phase; and (b) rates of error types (P-errors vs. M-errors) corresponding to the type of mismatching motion component (PATH or MANNER) when speakers chose the incorrect variant.

Regarding frequencies of correct responses, Fig. 2 illustrates that both language groups performed well above chance levels, with a majority of correct choices in both conditions and languages, notwithstanding slightly higher error rates in the non-verbal condition (English: 27\%, French: 31\%) relative to the verbal condition (English: 22\%, French: 19\%). However, this difference was not significant, as shown by an ANOVA indicating no effect of condition $(F(1,81)=3.34, p=0.07)$.

\section{INSERT FIG. 2}

As shown in Fig. 2, French speakers' error rates in the non-verbal task were slightly higher than those of other groups (French verbal, English non-verbal and verbal). However, this difference did not reach statistical significance, whether in the verbal condition $(F(1,39)=0.19, p=0.66)$ or in the non-verbal condition $(\mathrm{F}(1,42)=0.23, \mathrm{p}=0.63)$. Thus, participants' general memory of motion was neither significantly affected by condition, nor by their native language. 
As for error types, Fig. 3 shows error types across both conditions and languages, as a proportion of the total error rates within each group. Independently of language and condition, participants make significantly more errors with PATH than with MANNER, as confirmed by a $\chi^{2}$ test on proportions of error types $\left(\chi^{2}(1, \mathrm{~N}=191)=23.5, \mathrm{p}<0.0001\right)$.

\section{INSERT FIG. 3}

Regarding language differences, the slightly higher error rate detected in the French non-verbal group (see Fig. 2) as compared to all other language/condition groups corresponds to a greater proportion of errors involving MANNER, as would be expected on the basis of French speakers' tendency to omit this component in event expressions. However, a $\chi^{2}$ analysis indicated no significant effect of language on error rates $\left(\chi^{2}(1, N=191)=0.22, p=0.64\right)$. Similarly, condition (verbal vs. non-verbal) did not affect error types $\left(\chi^{2}(1, \mathrm{~N}=191)=0.1, \mathrm{p}=0.75\right)$.

\section{Discussion and conclusions}

This study tested the effect of language-specific properties across three types of tasks on a continuum ranging from maximally verbal to maximally non-verbal processes: oral event descriptions > verbal memory > non-verbal memory. Findings showed strong language effects on the most verbal task, motion event descriptions, but no significant impact of language on either verbal or non-verbal memory of motion events. These results were anticipated for the non-verbal cognitive task and in accordance with previous studies using interference paradigm. It remains to be explained why no language effects could be detected in the verbal condition of our memory task. One possible explanation may lie at least partly in our stimuli, some of which may have enhanced subjects' attention to MANNER and thereby partly neutralised differences between language groups in memory performance. This explanation is supported by two other results of our study. First, findings for verbal event description indicated that French subjects preferred MANNER-responses for items showing SKATE and JUMP more than would be expected on typological grounds. Thus, prior verbalisation of these MANNER-prominent items may have had the effect of diluting language-specific differences by unduly focussing subjects' attention on this component. Second, independently of language and condition, subjects had significantly more difficulty remembering PATH than MANNER, resulting in substantially fewer errors for the latter component.

To conclude, our findings suggest that motion event representation and verbalisation are malleable processes that are shaped dynamically both by bottom-up factors, such as visual salience (in line with e.g. Trueswell and Papafragou 2010), and by top-down factors. Amongst the latter, language-specific properties may play an important role that remains yet to be determined. In this respect, one of the major challenges of future research investigating the relation between language and cognition will be 
to find sophisticated experimental methods that provide means of tapping into non-verbal cognition whilst remaining sufficiently sensitive to and representative of natural cognitive processing to tease out language effects.

\section{References}

Athanasopoulos P and Bylund E (2013) Does grammatical aspect affect motion event cognition? A cross-linguistic comparison of English and Swedish speakers. Cognitive Science 37: 286-309

Choi S and Hattrup K (2012) Relative contribution of cognition/perception and language on spatial categorization. Cognitive Science 36: 102-129

Filipović L (2011) Speaking and remembering in one or two languages: Bilingual vs. monolingual Lexicalization and memory for motion events. International Journal of Bilingualism 15: 466485

Gennari SP, Sloman SA, Malt BC, Fitch WT (2002) Motion events in language and cognition. Cognition 83: 49-79

Hickmann M, Engemann H, Soroli E, Hendriks H, Vincent C (in press) Expressing and categorizing motion in French and English: Verbal and non-verbal cognition across languages. To appear in Ibarretxe-Antuñano I (ed) Motion and Space across Languages and Applications, John Benjamins: Amsterdam

Papafragou A, Hulbert J, Trueswell, J. (2008) Does language guide event perception? Evidence from eye movements. Cognition 108: 155-184

Papafragou A, Massey C, Gleitman L (2002) Shake, rattle, 'n' roll: The representation of motion in language and cognition. Cognition 84: 189-219

Slobin DI (2004) How People move: Discourse effects of linguistic typology. In: Moder CL and Martinovic-Zic A (eds) Discourse across languages and cultures. John Benjamins: Amsterdam, pp 195-210

Talmy L (2000) Toward a cognitive semantics: Typology and Process in Concept Structuring, 2nd edn., Vol. 2. MIT Press: Cambridge, MA

Trueswell JC and Papafragou A (2010) Perceiving and remembering events cross-linguistically: Evidence from dual-task paradigms. Journal of Memory and Language 63: 64-82 


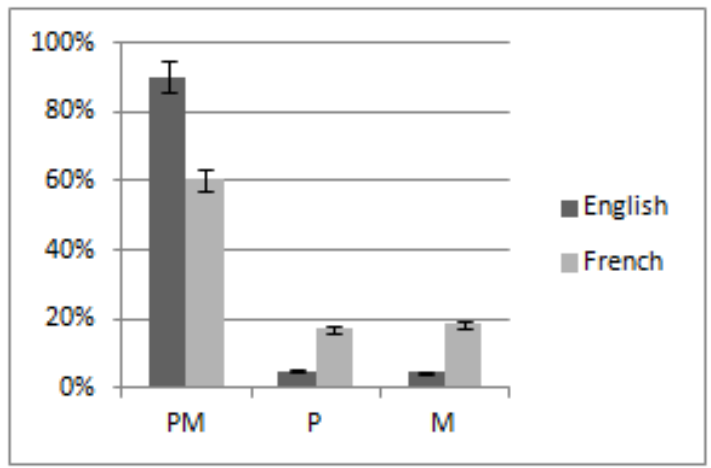

Fig. 1 Components encoded across languages

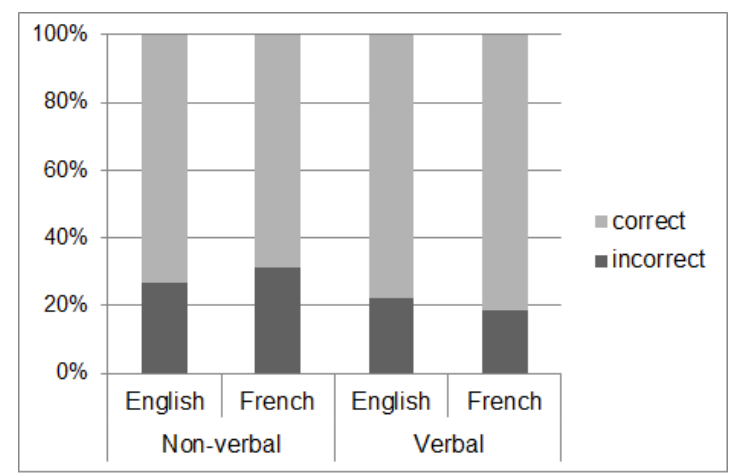

Fig. 2 Correct and incorrect responses across conditions and languages

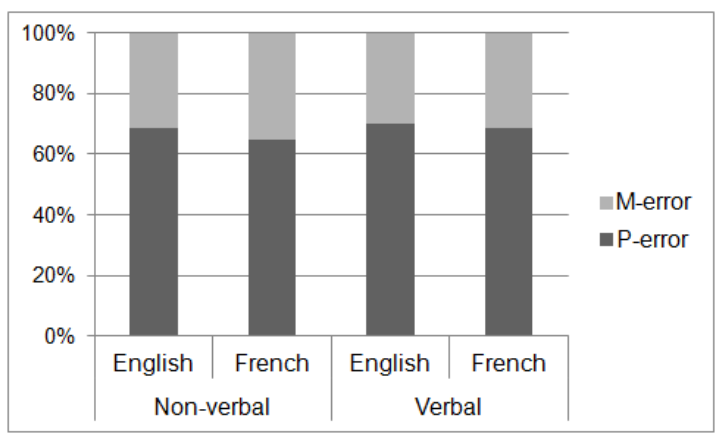

Fig. 3 Proportions of error types across conditions and languages 